\title{
LA COMPETENCIA DEL ESTADO Y DE LAS COMUNIDADES AUTONOMAS EN MATERIA DE DENOMINACIONES DE ORIGEN
}

\author{
por \\ Pedro de Miguel García
}

SUMARIO: I. INTRODUCCION.-II. LAS DENOMINACIONES DE ORIGEN: CONCEPTO Y REGULACION: 1. PRECISIONES CONCEPTUALES. 2. RÉGIMEN JURÍICO DE LAS DENOMINACIONES DE ORIGEN EN España: A) Ambito de aplicación. B) Concepto legal. C) Protección conferida. D) Modo de determinación.-III. EL ORDEN DE DISTRIBUCION DE COMPETENCIAS: 1. EL MARCO CONSTITUCIONAL. 2. LAS DETERMINACIONES ESTATUTARIAS. 3. LA CONCRECIÓN DE MEDIOS Y SERVICIOS ENUMERADOS EN LOS REALES DECRETOS DE: TRASPASOS: A) Los medios y servicios traspasados a las Comunidades Autónomas. B) Los servicios y funciones que continúan correspondiendo a la Administración del Estado. C) Las funciones que precisan la colaboración del Estado y las Comunidades Autónomas. Naturaleza de las "competencias exclusivas en colaboración».

\section{INTRODUCCION}

La pluralidad de intereses - tanto privados como públicos- que concurren en las denominaciones de origen hace necesaria la exis- 
tencia de un complejo aparato administrativo para su gestión y protección, de cuyo acierto en el montaje va a depender en gran medida el éxito de la correspondiente política en la materia.

En efecto, con las denominaciones de origen no sólo se busca la protección de los productores frente a la competencia desleal y la de los consumidores frente al fraude y el engaño - lo que de por sí ya obliga a toda una compleja actividad administrativa para la definición de los productos, la regulación de sus condiciones de producción y comercialización, la vigilancia en el cumplimiento de las normas y la represión de las prácticas ilícitas-, sino que al mismo tiempo dicha figura constituye una pieza nada desdeñable de las políticas económica, comercial y fiscal de las distintas Administraciones públicas con competencia en la materia.

Situados en esta singular encrucijada, las denominaciones de origen se convierten así, como consecuencia de los distintos intereses en juego concurrentes en ellas, en el lugar de encuentro de múltiples actuaciones estatales y comunitarias, cuyo análisis va a constituir el objeto central del presente trabajo, el cual irá precedido de unas consideraciones generales sobre su concepto y régimen jurídico, que servirán de marco al estudio de las referidas actuaciones.

\section{LAS DENOMINACIONES DE ORIGEN: CONCEPTO Y REGULACION}

\section{Precisiones conceptuales}

Las denominaciones de origen forman parte, junto con otras figuras, tales como las marcas de productos y servicios, los nombres comerciales y rótulos de establecimiento y las indicaciones de procedencia, de los llamados "signos distintivos», "medios fonéticos y visuales que consisten particularmente en palabras o imágenes aplicadas en la vida económica y social a la designación de personas o empresas, así como de productos o servicios que ellas proporcionan, a fin de facilitar su distinción y permitir al público su reconocimiento" (1).

Se trata de un signo distintivo caracterizado por el nombre geográfico del lugar de donde procede el objeto ofrecido al público

(1) Vid. Paul Mathèly: Le Droit français des signes distinctifs, Librairie du Journal des Notaires et des Avocats, París, 1984, pág. 3. 
y cuya naturaleza o cualidades son debidas a factores naturales o humanos propios de dicho lugar.

La denominación de origen coincide, pues, con la indicación de procedencia -figura con la que se confundió en un principio (2)-, en cuanto ambas utilizan como signo distintivo un nombre geográfico; pero a diferencia de esta última, no sólo garantiza la autenticidad del lugar, sino también una determinada calidad que el consumidor tiene la costumbre de encontrar en los productos originarios de aquél.

También se confunde en gran medida con la marca, entendida como "signo o medio material, cualquiera que sea su clase y forma, que sirva para señalar y distinguir de las similares los productos de la industria, el comercio y el trabajo" (3), si bien se singulariza de la misma por ser sustancialmente un derecho colectivo y por hacer referencia al origen, no tanto empresarial como geográfico, de los productos.

Conforme a estas notas, podemos entender por denominación de origen aquellos signos distintivos consistentes en el nombre geográfico de un país, región o localidad, que sirve para designar un producto originario de dicho lugar, y cuya calidad y caracteres son debidos al medio geográfico, incluidos los factores naturales y humanos (4).

(2) En el Derecho francés, pionero en la regulación de esta materia, la primitiva Ley de 6 de mayo de 1919, reguladora de las denominaciones de origen, consider6 a éstas como una mera indicación del origen geográfico sin ninguna referencia a la naturaleza específica del producto y menos aún a su calidad. El resultado fue desastrosos para los prestigiosos vinos de marca franceses al provocar un incremento enorme de la producción de vinos de inferior calidad que en su denominación se confundían con aquéllos. Fue precisamente para poner remedio a esta situación, y no por razones de logica abstracta, por lo que fue aprobada la Ley de 22 de julio de 1927, que exigió para los vinos, además de la recogida en el área a que hacían referencia, las condiciones, tanto del terreno como de las cepas, que se encontraban consagradas por los usos locales, leales y constantes, con lo que se abandono el nominalismo anterior introduciéndose así incidentalmente la idea de calidad en el concepto de la denominación de origen. Vid. J. Capus: L'evolution de la legislation sur les Appellations d'Origine. Genèse des Appellations Contrôlées, Larmot Editeur, 1947, pág. 16. Jean Marie Auby y Robert Plaisant: Le Droit des Appellations d'Origine. L'appellation Cognac, Librairies Techniques, 1974, págs. 43 y sigs.

(3) Definición dada por el artículo 118 del Estatuto de la Propiedad Industrial (Real Decreto-ley de 26 de julio de 1929). Carlos FERNÁNDEZ NovOA dice que: «El signo, asociado a los productos por el empresario, se convierte en una verdadera marca cuando la contemplación del signo desata en la mente de los consumidores las representaciones en tomo al origen empresarial, calidad $y$, en su caso, buena forma de los productos». Vid. autor citado: Fundamentos del Derecho de marcas, Ed. Montecorvo, 1984, pág. 25.

(4) Concepto extraído de la Ley francesa de 6 de mayo de 1919, modificada por la de 6 de julio de 1966, y sustancialmente coincidente con el dado en el Arreglo 
Se trata, pues, de un derecho privado de carácter colectivo, que corresponde a todas aquellas personas cuyas producciones respondan a los requisitos de autenticidad y calidad que se garantizan en el título.

\section{RÉGIMEN JURÍdico DE LAS DENOMINACIONES DE ORIGEN EN ESPAÑA}

La regulación de las denominaciones de origen en España se contiene en la Ley de 2 de diciembre de 1970, por la que se aprueba el Estatuto del Vino, Viñas y Alcoholes, y en su Reglamento de 23 de marzo de 1972.

Una exposición, aunque somera, de dicha regulación exige hacer referencia al ámbito de su aplicación, concepto legal, protección conferida y procedimiento de determinación.

\section{A) Ambito de aplicación}

A diferencia de lo que sucede en algunos países, como, por ejemplo, en Francia, donde la Ley de 6 de mayo de 1919, modificada por la de 6 de julio de 1966, es aplicada con carácter general a las denominaciones de origen de "los productos» procedentes de un país, región o localidad, en España dicha figura es objeto de regulación en uno de los títulos -el relativo a la "protección de la calidad»del citado Estatuto del Vino, Viñas y Alcoholes, lo que tiene como consecuencia el que su aplicación quede, en principio, restringida al ámbito propio de aquel Estatuto, aunque con la posibilidad - según se dice en la propia Ley - de que puedan acogerse a dicho régimen otros productos, como la uva de consumo directo y de mesa, la pasa, la sidra, los aguardientes simples y compuestos y demás productos a que se refiere la Ley distintos del vino; y todo ello sin perjuicio de la facultad atribuida al Gobierno para introducir definiciones de nuevos productos que, comprendidos en el ámbito de la Ley, no hubieran sido específicamente incluidos en su título preliminar (5).

de Lisboa de 31 de octubre de 1958. Vid. Paul MathèLy: Le Droit français..., ob. cit., página 878.

(5) Es a través de esta vía por la que ha ido extendiéndose el régimen de protección de calidad previsto en el Estatuto del Vino, Viñas y Alcoholes a otros productos distintos. Véase, a título de ejemplo, el Real Decreto de 18 de diciembre de 1985 en relación con los pimientos. 


\section{B) Concepto legal}

La Ley Reguladora del Vino, Viñas y Alcoholes, de 2 de diciembre de 1970, dice en su artículo 79 que, a efectos de la misma, se entenderá por denominación de origen «el nombre geográfico de la región, comarca, lugar o localidad empleado para designar un producto procedente de la vid, del vino o de los alcoholes de la respectiva zona que tenga cualidades y caracteres diferentes debidos principalmente al modo natural y a su elaboración y crianza».

El concepto coincide sustancialmente con el del Derecho unionista (6) expresado en el Arreglo de Lisboa de 31 de octubre de 1958, si bien resulta algo más restrictivo que éste, toda vez que, por un lado, no considera que puedan ser objeto de denominación de origen los nombres geográficos de países, y por otro - y esto es más importante-, incluye en el campo de acción de las denominaciones de origen no a todos los productos originarios de la respectiva zona, sino únicamente a los procedentes de la vid, del vino o los alcoholes, aunque, como acabamos de ver, este ámbito puede ser objeto de ulteriores ampliaciones.

En todo caso, importa destacar que en el concepto legal quedan claramente recogidos los dos elementos constitutivos de la denominación de origen a que hacíamos refeerncia al comienzo de este trabajo, a saber: la relación directa del producto con el lugar de donde procede y la existencia en aquél de caracteres específicos debidos a factores naturales o humanos propios del lugar de procedencia, con lo que la institución cumple cabalmente su finalidad esencial de garantizar al mismo tiempo el origen y la calidad del producto.

(6) El Derecho unionista viene dado básicamente por el Arreglo de Madrid de 14 de abril de 1891, y el de Lisboa de 31 de octubre de 1958, que le modifica. El objeto de aquél fue la represión de las indicaciones de procedencia falsas (las que no se corresponden con la realidad) y engañosas (las que correspondiéndose con la realidad, sin embargo, inducen al público a engaño), y preveía al efecto dos tipos de medidas: el embargo en la importación de cada país adherente de aquellos productos con indicaciones falsas o engañosas y la prohibición del uso de cualquier indicacion susceptible de engañar al público sobre la procedencia del producto. La finalidad del Arreglo de Lisboa fue la protección de las denominaciones de origen y su registro internacional, definiéndose al efecto aquéllas como ala denominación geográfica de un país, de una región o de una localidad que sirve para designar un producto originario de ellos y cuya cualidad o carácter son debidos exclusiva o esencialmente al medio geográfico, incluidos los factores naturales y humanos», definición que coincide literalmente con la adoptada por la legislación francesa si exceptuamos los calificativos «exclusiva o esencialmente». 


\section{C) Protección conferida}

El derecho a una denominación de origen, cuyo uso queda reservado exclusivamente para los productos que, de acuerdo con la Ley y con las disposiciones de cada denominación, figuran inscritos en los correspondientes registros, comporta el uso exclusivo de los nombres de las comarcas, términos, localidades y pagos que compongan las respectivas zonas de producción y crianza.

Los productos cubiertos por dicha potección, ya lo hemos visto, son originariamente los "procedentes de la vid, del vino o los alcoholes», si bien aquella protección puede extenderse a todos los productos agrícolas, transformados o no, e incluso a productos derivados de cualquier otra actividad económica, siempre que sus características se deriven esencialmente del lugar de producción.

El derecho otorgado es un derecho privado de carácter absoluto, como la marca, aunque de naturaleza colectiva, dada su pertenencia simultáneamente a todas aquellas personas cuyas producciones respondan a los requisitos de origen y calidad exigidos para el otorgamiento de la denominación. La protección conferida por este derecho es, pues, más fuerte que la obtenida mediante el juego de otros mecanismos, como la competencia desleal, toda vez que la inscripción en el registro correspondiente es título bastante para hacer frente a cualquier eventual usurpación.

\section{D) Modo de determinación}

Congruentemente con la doble finalidad a la que han de servir las denominaciones de origen, todas las actuaciones tendentes a la determinación de las mismas deben ir orientadas a precisar, por un lado, el área de protección, el cual no tiene por qué coincidir necesariamente con ninguna circunscripción administrativa o unidad geográfica, y por otro, las condiciones de producción, es decir, las calidades o caracteres del producto que dan derecho al uso de aquel título.

Esta doble tarea es realizada por el Reglamento particular de la denominación al señalar, según prescribe la Ley, la zona de producción y, en su caso, la de crianza, las variedades de uvas utilizables, los sistemas de cultivo, los de elaboración y crianza, producción máxima por hectárea y cuantos requisitos se consideren convenientes para garantizar la naturaleza y calidad de los productos. 
La elaboración del citado Reglamento incumbe hacerla a un Consejo Regulador designado provisionalmente por la autoridad administrativa, si estima oportuna la denominación, correspondiendo a dicha autoridad el reconocimiento de la referida denominación, la aprobación de su Reglamento y la Constitución del Consejo Regulador (7).

Nuestro sistema, a diferencia del francés, en el que cabe un procedimiento judicial y un procedimiento administrativo, es, pues, netamente administrativo, ya que es a las autoridades de esta naturaleza a las que corresponde el reconocimiento y reglamentación de las denominaciones de origen, y son estas mismas autoridades las que van a asumir la gestión de los intereses públicos en juego.

Analicemos el papel asignado a esas autoridades administrativas en el contexto de una fuerte descentralización política, como es la operada en nuestro país tras la aprobación de la Constitución en 1978.

\section{EL ORDEN DE DISTRIBUCION DE COMPETENCIAS}

Las competencias del Estado y de las Comunidades Autónomas, en materia de denominaciones de origen, derivan, según la hermenéutica de nuestro ordenamiento jurídico, en primer lugar, del marco establecido por la Constitución, inmediatamente después de las determinaciones estatutarias, y, por último, de la concreción de medios y servicios enumerados en los Reales Decretos de traspasos.

De esta triple fuente normativa que se nos presenta en forma de auténtica cascada, sólo la Constitución y los Estatutos de Autonomía tienen poder para fijar el orden de distribución de competencias, operación que se realiza primero por aquélla al separar las materias que pueden ser asumidas por las Comunidades Autónomas de las que corresponden en exclusiva al Estado, y luego por éstos al determinar las materias efectivamente asumidas por cada Comu-

(7) Los Consejos Reguladores son organismos de composicion mixta (el Presidente, Vicepresidente y dos vocales son designados por la Administración, mientras que los sectores vitícola, vinícola y exportador pueden contar con un número de hasta diez vocales), cuya naturaleza es la de órganos desconcentrados, si bien cuando adquieren un Estatuto de Autonomía se convierten en Entidades páblicas sujetas al Derecho privado con la autonomía necesaria para el cumplimiento de sus fines y con personalidad jurídica independiente, a los que se les asigna importantes funciones ejecutivas en la materia y se les dota de los oportunos poderes jurídicos para el cumplimiento de aquéllas. 
nidad dentro del marco que les permite la Constitución. Los Reales Decretos de traspasos, como ha dicho el Tribunal Constitucional en numerosas ocasiones (Sentencias de 7 de abril y 27 de octubre de 1983, de 28 de enero de 1986, etc.), no atribuyen ni reconocen competencias $\mathrm{y}$, por tanto, no pueden alterar o modificar el orden de distribución competencial fijado por la Constitución y los Estatutos de Autonomía, si bien constituyen una muy valiosa fuente de conocimiento para precisar los límites entre los respectivos ámbitos competenciales, ya que al relacionar los medios y servicios que el Estado transfiere a las Comunidades Autónomas para que éstas puedan ejercer las competencias asumidas, necesitan imprescindiblemente llevar a cabo una especificación muy detallada de las tareas en que se concretan aquellas competencias.

\section{El MaRCo CONSTITUCIONAL}

Los artículos 148 y 149 de la Constitución -preceptos en los que se contiene el orden básico de distribución de competencias entre el Estado y las Comunidades Autónomas- no hacen referencia alguna, de modo expreso y específico, a las denominaciones de origen.

Tal omisión constitucional sólo cabe interpretarse, a nuestro modo de ver, de una de estas dos manera: o se trata de una materia principal excluida intencionadamente de ambas listas, al objeto de que pueda entrar en juego la cláusula residual prevista en el apartado tercero del artículo 149 -lo que supondría la posibilidad de ser asumida desde el principio sólo por las Comunidades de primer grado-, o se trata de una materia accesoria subsumible dentro de algunas de las enumeradas en los repetidos artículos 148 y 149, y en cuyo caso debería seguir la suerte que, en el reparto de competencias, corren la materia o materias principales.

La primera interpretación parece ser la que ha sido adoptada por el Tribunal Constitucional en su Sentencia de 28 de enero de 1986 al resolver el conflicto positivo de competencias interpuesto por el Gobierno en relación con la Orden de 6 de abril de 1984 del Departamento de Agricultura, Ganadería y Pesca, de la Generalidad de Cataluña, por la que se modificaba, en parte, el Reglamento de la denominación de origen «Empordá-Costa Brava» y su Consejo Regulador. En su fundamento jurídico tercero, la sentencia afirma que «el Estado no se ha reservado de modo expreso y específico competencias sobre ella (la materia de denominaciones de origen) en los 
distintos párrafos del artículo 149, 1, de la Constitución Española $y$, en consecuencia, entra en juego el párrafo tercero del mismo artículo, que, en relación con Cataluña, sirve de enlace con el artículo $12,1,5$, inciso final, de su Estatuto, otorgándole así un título específico".

La consecuencia lógica que se deriva de esta interpretación, cuando trasciende del supuesto concreto que la produce, es que, al momento de aprobarse los Estatutos de Autonomía, la materia «denominaciones de origen" sólo podía estar disponible para las Comunidades Autónomas que no necesitaban dejar pasar cinco años para asumir la plenitud de competencias (competencias sobre todas las materias no incluidas en el art. 149), quedando, por tanto, vedada temporalmente para aquellas otras Comunidades que sí precisaban del transcurso de dicho plazo para alcanzar aquel techo competencial y que, durante el referido tiempo de espera, tenían que reducir sus aspiraciones competenciales únicamente a las materias comprendidas en el artículo 148.

El planteamiento descrito no se ajusta, sin embargo, al modo en que se ha producido el proceso estatutario, pues, como veremos con detalle después, todas las Comunidades Autónomas, a excepción de la de Castilla-León, han asumido desde el principio, en mayor o menor medida, competencias sobre la materia; por lo que si no se desea poner en tela de juicio - al menos, en este punto- la pulcritud de aquel proceso, habrá que convenir que la materia en cuestión debe considerarse comprendida dentro de alguna o algunas de las enumeradas en el artículo 148, respecto de las cuales, las Comunidades Autónomas de segundo grado sí podrían, sin traba alguna, asumir las competencias de la Constitución.

Esta distinta forma de interpretar el silencio constitucional puede encontrar el apoyo que necesita en las connotaciones que en mayor o menor medida las denominaciones de origen guardan con algunas de las materias del referido artículo 148, tales como la «agricultura», el "fomento del desarrollo económico de la Comunidad», las "aguas minerales y termales", las "ferias interiores» o la «pesca en aguas interiores, el marisqueo y la acuicultura, la caza y pesca fluvial», connotaciones, por otra parte, que también se extienden a materias incluidas en el artículo $149 \mathrm{y}$, por tanto, de la exclusiva competencia estatal, como las «relaciones internacionales», la «legislación mercantil», la «legislación sobre la propiedad indus- 
trial», el «comercio exterior» o las «bases y coordinación de la pla. nificación general de la actividad económica».

La permeabilidad de las denominaciones de origen, tanto a los títulos competenciales de las Comunidades Autónomas como a los del Estado, no constituye, por otra parte, ningún fenómeno excepcional en el contexto del orden de competencias establecido por la Constitución, habida cuenta de la frecuencia con que competencias autonómicas de carácter exclusivo se mueven en el llamado «marco referencial de competencias estatales». Lo singular, en el presente caso, estriba en la pluralidad de vínculos que unen a la materia objeto de nuestro estudio con los ámbitos competenciales del Estado y de las Comunidades Autónomas, Administraciones a las que corresponde tutelar la pluralidad de intereses de todo tipo que en aquélla confluyen y cuya coincidencia aquí determina la aparición de una nueva modalidad de competencia - la llamada «competencia exclusiva en colaboración"- de la que nos ocuparemos más adelante.

\section{LAS DETERMINACIONES ESTATUTARIAS}

La situación que se plantea en el plano constitucional por la concurrencia de títulos estatales y comunitarios sobre las denominaciones de origen no puede ser, en términos de pura lógica, abordada unilateralmente por una sola de las partes interesadas, antes al contrario reclama el empleo de fórmulas que posibiliten soluciones compartidas, como la ofrecida por nuestro ordenamiento jurídico al confiar aquella solución a una norma jurídica tan singular como los Estatutos de Autonomía, que forman parte al mismo tiempo del ordenamiento estatal y de los ordenamientos autonómicos, y en cuya elaboración intervienen, como es sabido, tanto el Estado como las Comunidades Autónomas.

Pues bien, a excepción del Estatuto de Autonomía de CastillaLeón (8), que declara las denominaciones de origen como materia asumible transcurridos cinco años o en virtud de Ley Orgánica de Delegación de Transferencias, el resto de los Estatutos -incluidos los correspondientes a las Comunidades Autónomas de segundo grado- han asumido desde el principio competencias en la materia, por considerar, sin duda $-\mathrm{y}$ así habrá que entenderlo si se quiere

(8) Vid. Estatuto de Autonomía de Castilla-León aprobado por Ley Orgánica 4/ 1983, de 25 de febrero, artículo 29, 1, 2." 
preservar la intachabilidad en este punto del proceso autonómico-, que la materia era subsumible dentro de alguna o algunas de las enumeradas en el artículo 148 (9).

No es por ello quizá casual que la materia «denominaciones de origen" figure en muchos Estatutos - si bien no en todos- unida a otras materias, como el comercio interior y la defensa del consumidor y usuario (Cataluña, Galicia y Comunidad Valenciana); la publicidad (Navarra); el comercio interior y la publicidad (País Vasco); las Cámaras de Comercio, Industria, Navegación, etc. (Andalucía); las indicaciones de procedencia (Castilla-La Mancha), o la propiedad industrial (Castilla-León). Incluso en los Reales Decretos de traspasos - aunque aquí la razón determinante de la afinidad es más bien debida a la peculiar manera de realizarse la división del trabajo en el seno de la Administración estatal- las denominaciones de origen suelen estar asociadas a una materia típicamente autonómica, cual es la «agricultura».

Sin embargo, lo más llamativo en este orden de cosas no es tanto la variedad de las materias con las que se relacionan las denominaciones de origen, sino la variedad de competencias funcionales asumidas sobre ellas por las Comunidades Autónomas en sus respectivos Estatutos.

En efecto, y dejando al margen el caso ya visto de Castilla-León, que ha decidido por el momento no asumir competencias en la materia, la lectura de los Estatutos nos ofrece el siguiente cuadro tipológico:

a) Cinco Comunidades tienen competencia exclusiva (se entiende normativa y ejecutiva) en colaboración con el Estado (País Vasco, Cataluña, Galicia, La Rioja y Comunidad Valenciana).

(9) Vid. Estatutos de Autonomía del País Vasco (Ley Orgánica 3/1979, de 18 de diciembre, art. 10, 27); Cataluña (Ley Orgánica 4/1979, de 18 de diciembre, artículo 12, 1,5); Galicia (Ley Orgánica 1/1981, de 6 de abril, art. 30, 1, 4); Andalucía (Ley Orgánica 6/1981, de 30 de diciembre, art. 13, 16); Principado de Asturias [Ley Orgánica 7/1981, de 30 de diciembre, art. 12,d)]; Cantabria [Ley Orgánica 8/1981, de 30 de diciembre, art. 24, c)]; La Rioja (Ley Orgánica 3/1982, de 9 de junio, artículo 8, 7); Murcia [Ley Orgánica 4/1982, de 9 de junio, art. 12, 1, c)]; Comunidad Valenciana (Ley Orgánica 5/1982, de 1 de julio, art. 34, 1, 5); Aragón (Ley Orgánica 8/1982, de 10 de agosto, art. 36, 2, 6); Castilla-La Mancha (Ley Orgánica 9/1982, de 10 de agosto, art. 33, 3); Canarias [Ley Orgánica 10/1982, de 10 de agosto, artículo 33, d)]; Navarra (Ley Orgánica 13/1982, de 10 de agosto, art. 44, 25); Extremadura (Ley Orgánica 1/1983, de 25 de febrero, art. 9, 3); Islas Baleares (Ley Orgánica 2/1983, de 25 de febrero, art. 11, 8); Madrid (Ley Orgánica 3/1983, de 25 de febrero, art. 28,3 ). 
b) Una Comunidad tiene competencia exclusiva (se entiende normativa y ejecutiva), sin perjuicio de la competencia del Estado en materia de comercio exterior, prevista en el artículo 149, 1, 10, de la Constitución. Todo ello en el marco de lo que establezca la legislación básica del Estado reguladora de las Corporaciones de Derecho público (Andalucía).

c) Una Comunidad tiene competencia exclusiva para su regulación (obsérvese que no se hace referencia a la ejecución) en colaboración con el Estado (Navarra).

d) Siete Comunidades tienen sólo competencia de ejecución o de función ejecutiva de la legislación del Estado en colaboración con el mismo (Principado de Asturias, Cantabria, Región de Murcia, Castilla-La Mancha, Canarias, Extremadura y Madrid).

e) Una Comunidad tiene sólo competencia ejecutiva de la legislación del Estado (Aragón).

f) Una Comunidad tiene el desarrollo legislativo y ejecución en el marco de la legislación básica del Estado y, en su caso, en los términos que la misma establezca (Islas Baleares).

No vamos a detenernos aquí en comentar las razones que puedan justificar una diversidad tan amplia de regímenes - cuya explicación, en última instancia, se encuentra en el principio dispositivo de nuestro sistema autonómico-, ni tampoco las imperfecciones y faltas de rigor que saltan a la vista al comparar los distintos textos estatutarios. Nos centraremos en algo, sin duda, de más interés, a los fines perseguidos por este trabajo, como es el conocimiento pormenorizado de los contenidos competenciales del Estado y las Comunidades Autónomas en la materia, el sentido que hay que dar a las llamadas «competencias exclusivas en colaboración con el Estado», que aparecen en 13 de los Estatutos de Autonomía, tareas para las cuales se hace necesario entrar en la última de las fuentes normativas antes enunciadas: los Reales Decretos de traspasos.

\section{LA CONCRECIÓN DE MEDIOS Y SERVICIOS ENUMERADOS EN LOS Reales DeCretos de traspasos}

A la vista del cuadro de competencias descrito cabría pensar que, dada la relación que debe existir entre las competencias asu- 
midas y los medios y servicios transferidos, los Reales Decretos reguladores de estos últimos permitirían establecer un cuadro de traspasos congruente con el de aquéllas.

Sin embargo, el cuadro resultante de los traspasos efectuados, al no haber sido tanto fruto de la lógica como de los avatares de los distintos momentos en que aquellos se han ido produciendo, ofrece una notable disimetría, y así no debe sorprender, por ejemplo, que el Real Decreto de 8 de febrero de 1984, sobre traspasos de funciones y servicios a Aragón, Comunidad que sólo asumió competencias de ejecución de la legislación del Estado, sea más amplio que el de 29 de diciembre de 1982, relativo a Galicia, Comunidad ésta que había asumido la competencia exclusiva, es decir, tanto las funciones normativas como las ejecutivas (10).

Un conocimiento detallado de la distribución de competencias en la materia exige analizar separadamente los medios y servicios traspasados a las Comunidades Autónomas, los servicios y funciones que continúan correspondiendo al Estado y las funciones que precisan la colaboración entre ambas instancias de poder.

\section{A) Los medios y servicios traspasados a las Comunidades Autónomas}

Las primeras transferencias tienen lugar con anterioridad a los Estatutos de Autonomía, e incluso en ocasiones a la propia Constitución, como consecuencia del establecimiento de los regímenes preautonómicos, en cuyos Reales Decretos-leyes de creación se preveía ya dicha posibilidad.

Sin embargo, la complejidad técnica que presentaba la articulación de tales transferencias, según se confiesa en los preámbulos de los primeros Reales Decretos de traspasos, determinó que se realizaran aquéllas en fases sucesivas, al objeto de posibilitar en el futuro, a medida que avanzasen los estudios y las propuestas, la ampliación de las materias traspasadas.

(10) En el Real Decreto de 8 de febrero de 1984 se incluyen dos funciones que no figuran en el de 29 de diciembre de 1982, a saber: la aprobación de las cuentas generales y los presupuestos presentados por los Consejos Reguladores, así como su tramitación al Ministerio de Agricultura, Pesca y Alimentación para su consentimiento y ratificación, y el estudio y proposición a dicho Ministerio de cuantas medidas afecten al régimen de plantación de viñas en las zonas de denominación de origen a que se refieren los artículos 38 y 39 del Reglamento del Estatuto de las Viñas, Vino y Alcohol, así como la colaboración en cuanto se refiere a lo que dispone el Título Primero de la Ley. 
Las primeras normas promulgadas al efecto tienen lugar en 1978. para Cataluña (23 de junio) y el País Vasco (15 de julio) de forma idéntica. En su virtud se transfieren a la Generalidad de Cataluña. y al Consejo General del País Vasco, en lo que afecta a sus respectivos ámbitos territoriales, las competencias que el Estatuto del Vino, Viñas y Alcoholes de 2 de diciembre de 1970 y disposiciones. complementarias confiaban al Instituto Nacional de Denominaciones de Origen (INDO), a excepción de una serie de materias que: debian seguir regulándose conforme a la legislación vigente (11). y de determinadas funciones, originariamente pertenecientes al INDO, que habrian de ejercerse coordinadamente con la Comunidad en la forma que reglamentariamente se estableciera (12).

Este régimen provisional se extiende, en términos idénticos, en 1979, a otros Entes Preautonómicos, como Aragón y Valencia (26 de enero), Andalucía (13 de febrero), Islas Baleares (7 de septiembre), Asturias (17 de diciembre), Extremadura (21 de diciembre) y Castilla-La Mancha (29 de diciembre), y en 1980, a Murcia (29 de febrero).

Entre tanto, el País Vasco y Cataluña han superado ya el régimen preautonómico con la promulgación de sus Estatutos de Autonomía (Leyes Orgánicas 3 y 4, ambas de 18 de diciembre de 1979), y se disponen a asumir nuevos servicios del Estado en la materia. Esta aspiración es satisfecha, respectivamente, por los Reales Decretos de 26 de septiembre de 1980 y 27 de febrero de 1981, los cuales, al tiempo que ponen en manos de aquellas Comunidades las competencias que los primitivos Reales Decretos de 23 de junio y 15 de julio de 1978, antes vistos, habían establecido que se regirían con-

(11) Las materias que debían seguir regulándose conforme a la legislación vigente eran las siguientes: aprobación definitiva de los Reglamentos de las denominaciones de origen, resolución sobre utilización de nombres y marcas que pudieran inducir a confusión e incoación e instrucción de expedientes por infracciones cometidas por empresas ubicadas en el territorio de la Comunidad en relación con denominaciones de origen extrañas a la misma.

(12) Las funciones, originariamente pertenecientes al INDO, que habrian de ejercerse coordinadamente con la Comunidad en la forma que reglamentariamente se estableciera eran las siguientes: orientar, vigilar y coordinar la producción, elaboración y calidad de los vinos y demás productos amparados por denominaciones de origen $\mathrm{u}$ otras denominaciones; vigilar en el territorio de la Comunidad la producción, elaboración y calidad de los productos que hayan de quedar sometidos al control de características de calidad no comprendidos en la función anterior; promover el reconocimiento de denominaciones que se estimen de interés general; velar por el prestigio de las denominaciones de origen y perseguir su empleo indebido; colaborar en las tareas de formación y conservación del catastro vitícola y vinícola que les sean encomendadas; colaborar, promover y efectuar los estudios adecuados..., y vigilar la actuación de los Consejos Reguladores y tomar o proponer las medidas necesarias para que éstos cumplan sus propios fines. 
forme a la legislación vigente o que habrían de ejercerse de un modo coordinado, instituyen todo un conjunto de mecanismos de cooperación con la Administración del Estado (13).

Los nuevos Reales Decretos son sustancialmente similares, aunque desde el punto de vista formal puedan apreciarse ciertas diferencias entre ellos (14), debidas sobre todo al deseo del segundo -el relativo a Cataluña- de corregir las deficiencias del primero, y van a servir de modelo, al igual que sucedió en el período preautonómico con los de 1978, para el resto de las Comunidades Autónomas (excepto Castilla-León, según hemos visto), al momento en que éstas, una vez promulgados sus Estatutos de Autonomía, reciban del Estado los correspondientes servicios.

Esta operación tiene lugar entre 1982 y 1985, y no obstante la sutancial coincidencia de contenido de todos los Reales Decretos de traspasos aprobados durante este tiempo, es posible apreciar algunas diferencias entre ellos, debidas, como ya hemos dicho antes, no tanto a la cantidad de competencias asumidas en los Estatutos como al momento en que se producen los traspasos.

En este sentido cabe distinguir tres períodos:

En el primero se inscriben los Reales Decretos de traspasos de 29 de diciembre de 1982 relativos a Galicia, Cantabria, Comunidad Valenciana y Extremadura, que confían a las respectivas Comunidades básicamente las mismas competencias (15) que sus predecesores

(13) Los mecanismos de cooperación con la Administración del Estado que se crean son los siguientes: el establecimiento de consultas previas necesarias para promocionar y autorizar las denominaciones de origen en su ámbito territorial; la determinación de un período con carácter general para constituir los Consejos Reguladores de las denominaciones de origen; la solicitud de colaboración y apoyo técnico del INDO y de otros organismos ministeriales relacionados en estas materias; la elevación al Ministerio de Agricultura, una vez aprobados, de los Reglamentos de las denominaciones de origen al objeto de que sean conocidos y ratificados de forma reglada por aquél, y la creación de mutuo acuerdo con el INDO de los mecanismos de coordina. ción que garanticen una mutua información y correcta gestión de las funciones asumidas.

(14) Las diferencias que se aprecian en el Real Decreto relativo a Cataluña se manifiestan, sobre todo, en su mejor sistematizacion al separar las funciones transferidas a la Generalidad de los mecanismos de colaboración y coordinación; en la sustitución que hace del listado de tareas por la referencia global a las funciones de la Administración Central en la materia, y, por último, en la renuncia a protagonismos tan poco pertinentes, como el de resolver sobre la utilización del nombre y marca que puedan inducir a confusión.

(15) Las competencias y funciones asumidas por estas Comunidades Autónomas son las siguientes:

a) Orientar, vigilar y coordinar la producción, elaboración y calidad de los vinos y demás productos amparados por denominaciones de origen o por otras denominaciones de acuerdo con la reglamentación básica en estas materias.

b) Vigilar en su ámbito territorial la producción, elaboración y calidad de los productos que hayan de quedar sometidos al control de características de cali- 
habían encomendado a Cataluña y País Vasco, si bien hacen gala de una técnica más depurada y dejan entrever algunos rasgos diferenciadores (16).

En el segundo se incluyen los Reales Decretos de traspasos relativos a Murcia, Islas Baleares, Andalucía y Castilla-La Mancha (5 de octubre de 1983); La Rioja (13 de octubre de 1983); Madrid (2 de noviembre de 1983); Canarias (7 de noviembre de 1983), y Aragón (8 de febrero de 1984), que transcriben literalmente las mismas: funciones que figuran en los del período anterior, incorporando dos nuevas que el Reglamento de las Viñas, Vino y Alcohol de 23 de marzo de 1972 había conferido al INDO, pero que no habían sido. recogidas de forma expresa hasta entonces en los Reales Decretos: de traspasos y que se refieren a la aprobación de las cuentas y presupuestos de los Consejos Reguladores y al estudio y proposición al Ministerio de Agricultura, Pesca y Alimentación de cuantas medidas afecten al régimen de plantación de viñas en las zonas de denominaciones de origen.

dad no comprendidas en el punto anterior, de acuerdo con las normas básicas y según las previsiones que la legislación estatal establezca.

c) Promocionar y autorizar, estableciendo las consultas previas necesarias con ef Ministerio de Agricultura, Pesca y Alimentación, las denominaciones de origen.

d) Velar por el prestigio de las denominaciones de origen y perseguir su empleo indebido.

e) Colaborar en las tareas de formación y conservación del catastro vitícola y vinícola.

f) Colaborar, promover o efectuar los estudios adecuados para la mejora de la producción y de la elaboración de los productos protegidos por denominaciones de origen, así como los estudios de mercado para los mismos y la promoción del consumo.

g) Vigilar la actuación de los Consejos Reguladores y tomar o proponer las medidas necesarias para conseguir que éstos cumplan sus propios fines.

h) Aprobar los Reglamentos de las denominaciones de origen y elevarlos al Ministerio de Agricultura, Pesca y Alimentación para su conocimiento y ratificación, lo que éste hará siempre que aquéllos cumplan la normativa vigente.

i) Constituir los Consejos Reguladores de denominaciones de origen de su exclusivo ámbito territorial según la normativa vigente y dentro del período establecido de común acuerdo con todas las Comunidades Autónomas, con carácter general para todos los Consejos. En los Consejos Reguladores de denominaciones específicas y denominaciones de origen cuyo ámbito supere el de una Comunidad Autónoma, éstas estarán representadas de acuerdo con la normativa que sobre el tema se establezca.

j) Incoar e instruir los expedientes por infracciones cometidas por empresas ubicadas en su territorio y no inscritas en los registros de denominación de origen contra denominaciones de origen incluidas en su ámbito territorial. La resolución se efectuará conforme a la legislación vigente en estas materias.

(16) Entre los rasgos diferenciadores merece citarse, en primer lugar, la necesidad de conformar a la reglamentación básica y a la legislación estatal en la materia, las funciones de orientación, vigilancia y coordinación sobre la producción, elaboración y calidad de los productos objeto de su competencia, y en segundo lugar, la renuncia, como ya hiciera Cataluña, a resolver sobre la utilización de nombre y marca que pueda inducir a confusión. 
En el tercero, finalmente, se sitúa, un tanto descolgado en el tiempo, el Real Decreto de traspasos a Navarra, de 18 de diciembre de 1985, cuya singularidad respecto de los anteriores consiste en la introducción de simples, aunque numerosas, modificaciones de detalle (17).

\section{B) Los servicios y funciones que continúan correspondiendo a la Administración del Estado}

En todo proceso de traspasos, y en especial en aquellos en que el objeto de los mismos no agota todos sus contenidos materiales $\mathrm{y}$ funcionales, el listado de funciones transferidas debe contemplarse con el de las reservadas.

Esta delimitación negativa del ámbito competencial autonómico empezó haciéndose de una forma un tanto marginal y residual en los Reales Decretos relativos al País Vasco y Cataluña, pero acabó en seguida por formalizarse en un listado independiente que, de manera uniforme, fue aceptado en los restantes Reales Decretos de traspasos, según los cuales, el papel reservado al Estado en la materia queda reducido, por un lado, a aquellos aspectos que trascienden al interés nacional, ya sea por la necesidad de mantener un mínimo de igualdad normativa en todo el territorio, ya sea por afectar a relaciones entre Estados, y, por otro, a los que siendo de interés de las Comunidades Autónomas, desbordan, no obstante, las posibilidades de acción de las mismas en orden a su gestión y defensa (18).

(17) Las modificaciones introducidas por el Real Decreto de traspasos a Navarra de 18 de diciembre de 1985 son las siguientes: desaparición de la referencia a las normas básicas y a la legislación estatal en las funciones de orientación, vigilancia y coordinación de la producción, elaboración y calidad de los productos objeto de su competencia; extensión del régimen de las denominaciones de origen a uotras denominaciones»; inclusión de la competencia estatal para ratificar los Reglamentos de las denominaciones de origen, no en el apartado relativo a las funciones retenidas por el Estatuto, sino en el de las asignadas a la Comunidad como ámbito vedado a éstas, y, finalmente, supresión del requisito de la ratificación estatal en los actos comunitarios de aprobación de las cuentas generales y los presupuestos de los Consejos Reguladores.

(18) En el primer caso se encuentran las tres funciones que figuran a continuación en primer lugar, y en el último, las que se incluyen seguidamente:

a) El establecimiento de la reglamentación básica, oídas, en su caso, las Comunidades Autónomas, para la producción, elaboración y calidad de los productos amparados por denominaciones de origen sometidos al control de características de calidad no comprendidas en denominaciones de origen.

b) El establecimiento de la legislación básica reguladora de las normas de funcionamiento de los Consejos Reguladores. 
C) Las funciones que precisan la colaboración del Estado y las Comunidades Autónomas. Naturaleza de las "competencias exclusivas en colaboración»

En los Reales Decretos de traspasos al País Vasco y Cataluña, se: prevé todo un juego de relaciones interadministrativas, como el establecimiento de consultas previas con la Administración Centraf. al momento de promocionar y autorizar las denominaciones de origen en el territorio comunitario, el conocimiento y ratificación por el Ministerio de Agricultura de los Reglamentos de denominaciones de origen a efectos de su defensa en el ámbito nacional e internacional, la creación de mecanismos de coordinación para garantizar la mutua información y correcta gestión de las funciones asumidas de mutuo acuerdo, el establecimiento del período de constitución de los Consejos Reguladores, la solicitud de colaboración y apoyo técnico estatales y la coparticipación en la tramitación de los expedientes por infracciones. (En el caso del País Vasco se incluye, además, la colaboración en las tareas de formación y conservación del catastro vitícola y vinícola, así como en los estudios relativos a los: productos protegidos por las denominaciones de origen.)

Estas relaciones interadministrativas serán recogidas por los Estatutos posteriores, con una sistemática más rigurosa, dentro de la cual se agrupan en un apartado independiente titulado «Funciones en que han de concurrir la Administración del Estado y la Comunidad Autónoma y forma de cooperación», una serie de funciones (establecimiento de período de constitución para los Consejos Reguladores, gestión de exacciones parafiscales y recaudación de multas, coordinación de materias transferidas y apoyo técnico estatal)

c) Las relaciones internacionales en materias de denominacion de origen y específicas.

d) La resolución sobre utilización de nombres y marcas que puedan confundir al consumidor o causar perjuicios a terceros en materia de denominaciones de origen y denominaciones específicas.

e) La ratificación y asunción de los Reglamentos de denominación de origen y denominaciones específicas a los efectos de su promoción y defensa en el ámbito nacional e internacional.

f) La vigilancia de las actuaciones de los Consejos Reguladores para ejercer eficazmente la defensa de las denominaciones de origen fuera del ámbito territorial.

g) La instrucción y resolución de expedientes por infracciones cometidas por empresas ubicadas en una Comunidad Autónoma en relación con denominaciones de origen de otra Comunidad Autónoma. La incoación del expediente podrá ser realizada por la Administración del Estado o por cualquiera de las Comunidades afectadas.

h) La coordinación de los Consejos Reguladores. 
cuyo desarrollo coordinado se confía, en los Reales Decretos de traspasos aprobados en 1982, a «los mecanismos que en cada caso se señalan», y en los posteriores a dicho año, al "órgano colegiado que sea reglamentariamente establecido por el Ministerio de Agricultura, Pesca y Alimentación con participación de todas las Comunidades Autónomas».

Es precisamente en el marco de estas relaciones interadministrativas donde se desarrollan las llamadas en los Estatutos de Autonomía "competencias exclusivas de las Comunidades Autónomas en colaboración con el Estado» o, si se permite la expresión elíptica: «competencias exclusivas en colaboración».

$¿$ Cuál es la naturaleza de estas competencias, que en el plano de la pura lógica parecen resultar incoherentes por la contraposición que existe entre los términos que integran la locución?

En nuestro orden de distribución de competencias cabe que una materia sea asumida en su plenitud por una Comunidad Autónoma y resultar su ejercicio condicionado o limitado, ya por el marco más amplio de las competencias estatales (caso de la agricultura en relación con la ordenación general de la economía), ya por la función coordinadora del Estado (sanidad); que una misma materia esté atribuida a ambas instancias territoriales, bien de forma indiferenciada (cultura), bien diferenciadamente (carreteras); que el objeto de distribución de competencias no sea la materia en sí, sino aspectos funcionales de la misma (legislación y ejecución en materia laboral) o incluso simples grados de aquellos aspectos (legislación básica y de detalle en materia de montes)...

El resultado de esta compleja situación es la existencia de una diversidad de títulos competenciales (competencias plenas, exclusivas, compartidas, concurrentes, etc.), sobre cuyos significados existe una notoria confusión doctrinal.

A esta variedad de competencias hay que añadir las competencias exclusivas en colaboración, a las que aluden numerosos Estatutos cuando se refieren a las denominaciones de origen, y cuyos rasgos diferenciadores han sido destacados por el Tribunal Constitucional en la Sentencia, ya antes citada, de 28 de enero de 1986, dictada a propósito de la Orden de la Consejería de Agricultura, Ganadería y Pesca de la Generalidad de Cataluña de 6 de abril de 1984, que modificaba el Reglamento de la denominación de origen «Empordá-Costa Brava», sin que se hubiera producido la previa consulta con la Administración Central ni la ratificación del Minis- 
terio de Agricultura, exigidas, como hemos visto, por los apartados. B, 2, a) y c), del anexo del Real Decreto 479/1981, de 27 de febrero, sobre traspaso de servicios del Estado a la Generalidad de Cataluña. en materia de denominaciones de origen.

Solicitada por el Abogado del Estado la anulación de dicha. Orden, por considerar que había invadido competencias estatales, el Tribunal Constitucional la declaró válida afirmando que no lesio-. naba competencia estatal alguna, toda vez que el deber de colabora-ción de la Generalidad, consistente en remitir los Reglamentos al Ministerio de Agricultura, no es condición de validez de la norma. ni condición tampoco para su general eficacia tras la correspondiente publicación. Tal «deber de remisión» de la Generalidad -añade- está orientado únicamente a hacer posible la competencia de colaboración estatal, consistente, a su vez, en ratificar o no los. Reglamentos, disyuntiva que nace desde que el Reglamento -en este caso, la Orden - le haya sido remitido o notificado. Por todo. ello - concluye el Tribunal-, la Orden en cuestión fue válida y eficaz desde su publicación en todo, salvo en lo concerniente a la ratificación y a sus efectos.

De la doctrina expuesta pueden extraerse los siguientes rasgos. conformadores de la relación de colaboración entre entes públicos, en su aplicación al supuesto que constituye el objeto de la sentencia:

a) Las actuaciones de dichos entes no son intercambiables, sino. complementarias («lo que puede realizar uno de los entes colabora-. dores no lo debe hacer el otro").

b) La complementariedad de aquellas actuaciones no permite situaciones de injerencia ("las competencias exclusivas en colaboración no implican una previa diferenciación de competencias parciales que el Estado haya de coordinar») ni de subordinación (la expresión contenida en los Estatutos no es "con la colaboración de", sino «en colaboración con»), sino que supone simplemente que «deben ser realizadas bilateralmente en régimen de cooperación específica».

c) Finalmente, la realización bilateral de dichas actuaciones no opera en el marco de la recíproca tendencia, ya que la validez y eficacia de una actuación son totalmente independientes de la validez y eficacia de la actuación complementaria («el deber de colaboración - rectamente entendido- consiste en facilitar al máximo las. competencias del otro ente»). 
El supuesto contemplado -el conocimiento previo y la ratificación por parte de la Administración estatal de los Reglamentos de denominaciones de origen aprobados por las Comunidades Autónomas- no agota, ni mucho menos, la totalidad de las técnicas o formas jurídicas mediante las que se canalizan las relaciones de cooperación y colaboración impuestas en materia de denominaciones de origen por trece de los Estatutos de Autonomía. Existen otras muchas que aparecen recogidas, como hemos visto, en los Reales Decretos de traspasos, incluso en los correspondientes a aquellas Comunidades cuyos Estatutos no hacen una referencia expresa a esta modalidad de competencia; fenómeno éste, por otro lado, que no debe extrañarnos, dada la generalización que se ha hecho de las fórmulas de cooperación en la práctica de las transferencias.

En este orden de cosas conviene advertir, no obstante, sobre la extralimitación en que pueden incurrir los Reales Decretos de traspasos al determinar las técnicas o instrumentos de colaboración, pues, como ha señalado el Tribunal Constitucional en la sentencia comentada, tal operación «no puede suponer en ningún caso una modificación del orden competencial establecido ni puede introducir nuevos principios o criterios de relación no previstos en la Constitución o en los Estatutos, o que no se conformen con los establecidos en una y otros", debiéndose, además, interpretar dichas técnicas instrumentales «de acuerdo con las correspondientes previsiones constitucionales y estatutarias». 
